\title{
IN-VITRO INTERACTIONS OF HUMAN CHONDROCYTES AND MESENCHYMAL STEM CELLS, AND OF MOUSE MACROPHAGES WITH PHOSPHOLIPID-COVERED METALLIC IMPLANT MATERIALS
}

\author{
R Willumeit $^{* *}$, M Schossig ${ }^{1}, \mathrm{H}_{\text {Clemens }}^{2}$, and F Feyerabend ${ }^{1}$ \\ ${ }^{1}$ GKSS Research Center, Max-Planck-Str.1, 21502 Geesthacht, Germany \\ ${ }^{2}$ Montanuniversität Leoben, Department of Physical Metallurgy and Materials Testing, Franz-Josef-Strasse 18, A - \\ 8700 Leoben, Austria
}

\begin{abstract}
Phospholipid-coatings on metallic implant surfaces were evaluated in terms of adhesion, proliferation and matrix production of skeletal cells, and of macrophage stimulation. The working hypothesis is that mimicking a model biomembrane by phospholipids on surfaces to which cells adhere, the surface recognition by surrounding cells is altered. In this study, 1) mirror-like polished Ti-6Al-7Nb and 2) porous Ti-6Al-4V specimens were covered with the phospholipids POPE (palmitoyl-oleoyl phosphatidylethanolamine) and POPC (palmitoyl-oleoyl phosphatidylcholine), and the interactions of a) human articular chondrocytes (HAC), b) human mesenchymal stem cells (HMSC), and c) mouse macrophages (RAW 264.7) were tested in vitro.

On POPE-covered polished surfaces adherence of HAC ( $42 \%$ of seeded cells after $2 \mathrm{hrs}$ ) and metabolic activity (MTT after 3 days) were reduced, while on porous surfaces 99\% HAC adhered, and metabolic activity was significantly increased, compared to respective native surfaces. On both POPE-covered surfaces the chondrocyte phenotype was present. After 3 weeks of chondrogenic differentiation, cartilage matrix production (measuring chondroitin sulphate per HAC number) was significantly increased by about $30 \%$ on both POPE-covered metallic surfaces. On both POPCcovered surfaces nearly no adhering and surviving HAC were found.

HMSC grown on POPE-covered porous substrates showed osteogenic differentiation by improved osteopontin and collagen I expression in RT-PCR, and osteocalcin fluorescence and bone nodule formation was only detectable on POPE-covered porous surfaces. In contrast to POPC and other phospholipids used as positive controls, POPE did not stimulate the NO production in mouse macrophage cultures. We therefore conclude that a phospholipid coating by POPE shows potential as surface modification for metallic implant materials.
\end{abstract}

Keywords: Phospholipid-coatings, porous Ti-6Al-4V, polished Ti-6Al-7Nb, chondrocytes, mesenchymal stem cells, macrophages, in vitro tests.

Address for correspondence*

PD Dr. Regine Willumeit,

GKSS Research Centre, Institute for Material Research, Department of Macromolecular Structure Research,

Max-Planck-Str. 1,

21502 Geesthacht, Germany.

Telephone: 0049415287 1291,

Fax: 00494152871356

E-mail: regine.willumeit@gkss.de
Permanent implants, such as metallic hip prostheses, are widely used and successfully implemented in medicine. Due to modifications of material properties, design and optimisation of a variety of surface parameters, the durability of these implants has been improved significantly. Still, a lifetime of more than 20 years is hardly ever reached. This is not in the first place due to a total failure of the implant, but rather because particles which are used to structure the implant surface, or which are worn-off the articulating surfaces, induce a macrophage reaction which disturbs bone remodelling (Wooley and Schwarz, 2004; Zreiqat et al., 2003). In addition, the need for permanent or more long-lasting implants is growing, because younger patients already need implants, and the life expectancy of older patients is increasing.

The efforts are manifold to develop new implant surface modifications which may prolong the life span of an implant, or shorten the recovery time of a patient by quicker and more stable implant incorporation. Among them are approaches to cover the metallic implants with hydroxylapatite (Chen et al., 1998), or with peptide or proteins (adhesion sequences like 'Arg-Asp-Gly' (RGD), collagen, growth factors; Jennissen et al., 1999; Otto et al., 2004; Roessler et al., 2001), or to produce a nanostructured surface.

In this paper, an alternative approach is proposed and discussed: the use of a cell biomembrane mimic. Cell membranes consist of approximately $60 \%$ proteins and $40 \%$ lipids. The importance of proteins is widely accepted, while the role of lipid layers is not fully acknowledged. From a biophysical point of view a strong interaction between membrane proteins and their surrounding phospholipid bilayer is found, and the two-dimensional liquid crystalline lattice together with the fluidity of the membrane is a prerequisite for the proper function of membrane proteins. Evidence is mounting that sensing of membrane phospholipid properties by proteins is possible (Anishkin and Kung, 2005; Kung, 2005), and this is the reason for specific protein functions (Booth, 2005). Signalling processes are considered to depend on specific microdomains (lipid rafts) formed by membrane phospholipids and proteins (see for example: Simons and Toomre, 2000). Also, the membrane structure can be influenced severely by even small peptides, if they interact with the phospholipids, as it is the case for peptide antibiotics (Willumeit et al., 2005). Therefore, we assume that cell interactions are not only determined by protein interactions, but also influenced by the phospholipid bilayer of the cell membrane. 
In this study we show, as a proof of principle, that even a simple model phospholipid membrane system can influence significantly the cell behaviour on metallic biomaterials. As a test phospholipid POPE (palmitoyloleoyl phosphatidyl-ethanolamine) is chosen. This phospholipid has been shown to be essential for cytokinesis (Emoto et al., 2005), but further physiological functions are not known. It also shows interesting biophysical properties (like the formation of an inverse hexagonal phase) and is found in minor amounts in erythrocyte membranes. The negative control is POPC (palmitoyloleoyl phosphatidyl-choline), one of the major phospholipid components of erythrocyte membranes which is known to prevent blood cell interaction and coagulation (Durrani et al., 1986).

Human Articular Chondrocytes (HAC) were chosen as an in vitro model system mainly because they show a morphological indication about their status of differentiation (Glowacki et al., 1983; Holtzer et al., 1960). As a more realistic model system for implant attachment to the skeleton, the interaction of Human Mesenchymal Stem Cells (HMSC) with these phospholipid coatings was evaluated. The well known influence of the substrate surface morphology (Boyan et al., 1996) was taken into account by cultivating the cells on mirror-like polished Ti-6Al-7Nb and on porous Ti-6Al-4V specimens. The cell interaction with the different surfaces was investigated in terms of plating efficiency, cell adhesion, proliferation and matrix production. For HMSC, RT-PCR analysis of bone marker proteins was performed. To evaluate if the phospholipids activate macrophages, NO-measurements were performed on mouse macrophage cultures. Here not only the two previously mentioned phospholipids were tested, but also POPS (palmitoyl-oleoyl phosphatidylserine) and POPG (palmitoyl-oleoyl phosphatidylglycerol) as positive controls. The first phospholipid, even though abundant in eukaryotic cell membranes, is known to activate macrophages (Williamson and Schlegel, 2002). The second phospholipid is of bacterial origin and also considered a positive control for macrophage activation.

\section{Materials and Methods}

\section{Metallic culture substrates}

Mirror-like polished Ti-6Al-7Nb discs, and porous Ti-6Al$4 \mathrm{~V}$ cuboids were used as culture substrates. Ti-6Al-7Nb discs (10 mm diameter, $1 \mathrm{~mm}$ thickness) were cut from a compact round bar (F.W. Hempel, Oberhausen) and surface ground, using $30 \mu \mathrm{m}$ (P500 SiC), $18 \mu \mathrm{m}$ (P1000 SiC), 10 $\mu \mathrm{m}$ (P2500 SiC) particle size grinding papers. They were finally polished with $1.0 \mu \mathrm{m}$ diamond-paste, and mirrorfinished with $0.05 \mu \mathrm{m} \mathrm{SiO}_{2}$-paste.

The porous cuboid culture substrates $(5 \times 5 \times 2 \mathrm{~mm})$ were cut from the bulk material below by electro-discharge machining (EDM). The porous material was manufactured by Boeing using the low-density-core (LDC) process as described by Schwartz et al. (1998). This process is based on an entrapped gas technique. Here, Ti-6Al-4V powder is filled into a specially designed can. Subsequently, the can is outgassed and then charged with pressurized Argon gas. The gas pressure is sealed into the can which is then hot-isostatically pressed (HIPed). During HIPing a fully consolidated material is obtained. The dense, gas containing billet is then hot-worked into final shape. In our case, hot-rolling was used to produce a sheet. Subsequent to rolling, the sheet is annealed for 6-24 hours at a temperature equivalent to 0.6 times the melting point. At the elevated temperature the material is soft and the entrapped gas pressure is high enough to expand the surrounding material. A porous body is obtained, exhibiting $20-40 \%$ of non-connected porosity, typical pore diameters ranging from 10 to $200 \mu \mathrm{m}$. To image and measure this porous structure, an approximately $1.5 \mathrm{~mm}$ high and $1 \mathrm{~mm}$ diameter rod-like sample was produced for X-ray microtomography ( $\mu \mathrm{CT}$, at beamline W2, HASYLAB, DESY, Hamburg, Germany).

The disc- and cuboid-shaped culture substrates were ultrasonically cleaned for 30 minutes in concentrated HELMANEX-solution (Hellma GmbH \& Co KG, Mühlheim, Germany), followed by intense rinsing in acetone (Merck, Darmstadt, Germany), double-distilled water (Millipore, Bilerica, Massachusetts, USA) and ethanol (Merck, Darmstadt, Germany). If the specimens, due to the limited number of available growth substrates, were used repeatedly, the metallic samples were additionally washed in a $1 \mathrm{mM}$ in chloroform-methanol $(80: 20)$ solvent to remove possible (lipid) impurities. Finally the samples were dried at $40^{\circ} \mathrm{C}$ in a vacuum oven.

\section{Phospholipids for coating}

In the nomenclature of the chosen phospholipids, the first two letters 'PO' indicate the acyl chains palmitoyl and oleoyl (16:0/18:1). They resemble the most abundant hydrocarbon chains in cell membranes. The last two letters are the abbreviations of the phospholipid head group.

For the determination of cell growth and metabolic activity, the two phospholipids POPE (1-palmitoyl-2oleoyl-sn-glycero-3-phospho-ethanolamine), and POPC (1-palmitoyl-2-oleoyl-sn-glycero-3-phospho-choline) (Sigma-Aldrich-Chemie, Taufkirchen, Germany, $1 \mathrm{mM}$ ) in chloroform-methanol $(80: 20)$ solvent were applied to both metallic culture substrates. At room temperature and ambient atmosphere, polished disc surfaces were totally covered, and porous cuboids were soaked for 30 minutes with $30 \mathrm{~mL}$ of the phospholipid solution. Then the solvent was evaporated by drying the specimens overnight at $40^{\circ}$ $\mathrm{C}$ under vacuum. As controls, specimens without phospholipid covering were tested. In order to visualize better POPE influence on HAC adhesion, one polished Ti-6Al-7Nb disc was only half-dipped into the phospholipid solution.

For the determination of the influence of various phospholipids on macrophages, in addition to POPE and POPC, also POPS (1-palmitoyl-2-oleoyl-sn-glycero-3[phospho-L-serine]) and POPG (1-palmitoyl-2-oleoyl-snglycero-3-[phospho-rac-(1-glycerol)] (sodium salt)) (Sigma-Aldrich Chemie, Taufkirchen, Germany) were used. The coating was performed by applying $10 \mathrm{~mL}$ of a $1 \mathrm{mM}$ POPE, POPC, POPS and POPG in 
isopropanol:ethanol (50:50) solution (VWR International, Darmstadt, Germany) on plastic culture wells. The solvent was evaporated for 1 hour at room temperature, and the wells then dried overnight at $60^{\circ} \mathrm{C}$. As control, uncovered wells were used.

\section{Cell culture systems}

Cell culture of human articular chondrocytes (HAC) Cartilage samples were obtained at autopsy from donors within 24 hours after death, under a protocol approved by the local ethic committee. Primary chondrocytes were isolated by digestion with trypsin/EDTA (Invitrogen $\mathrm{GmbH}$, Karlsruhe, Germany), hyaluronidase $(0.5 \mathrm{mg} / \mathrm{mL})$ and collagenase $(0.5 \mathrm{mg} / \mathrm{mL}$; Sigma-Aldrich Chemie, Steinheim, Germany) for two hours. Chondrocytes in the supernatant were washed and resuspended in Dulbecco's modified Eagle's medium (DMEM; Invitrogen GmbH, Karlsruhe, Germany) containing $10 \%$ FBS (PAA Laboratories, Linz, Austria), $10 \mathrm{ng} / \mathrm{mL}$ basic fibroblast growth factor (bFGF; R\&D Systems, Wiesbaden, Germany), $1 \%$ penicillin and $100 \mu \mathrm{g} / \mathrm{mL}$ streptomycin (Invitrogen $\mathrm{GmbH}$, Karlsruhe, Germany). The remaining cartilage was digested again two times overnight. All retrieved primary chondrocytes were cultured at $37^{\circ} \mathrm{C}$ under $5 \% \mathrm{CO}_{2}$ atmosphere at a density of $5000 \mathrm{cells} / \mathrm{cm}^{2}$ in T175-flasks (Nunc GmbH, Wiesbaden, Germany). After 24 hours non-adherent cells were discarded. Medium was replaced every $2-3$ days. The cells were passaged at confluence. Cells used for the experiments originated from the $3^{\text {rd }}$ passage.

\section{Cell culture of human mesenchymal stem cells (HMSC)}

HMSC were obtained from bone marrow transplantation from donors under a protocol approved by the local ethic committee. Cells left in the filter stages of the marrow bags after transplantation were washed out with DMEM. Mesenchymal cells with nuclei were separated by ficoll gradient centrifugation (Biocoll solution, density $1.077 \mathrm{~g} /$ $\mathrm{mL}$; Biochrom AG, Berlin, Germany). The obtained cell population was further selected by adhesion to T75 cell culture flasks (Nunc GmbH, Wiesbaden, Germany). Nonadhesive cells were discarded. Culture medium (DMEM with $10 \% \mathrm{FBS}$, penicillin and streptomycin) was changed every three days; cells were passaged at $70 \%$ confluence. The cells used in the assays were from the $3^{\text {rd }}$ passage.

\section{Cell culture of mouse macrophages (cell line RAW 264.7)}

These tumour-derived mouse cells are capable of producing cytokines like nitric oxide (NO) and tumour necrosis factor a (TNF- $\alpha$ ) as an in vitro immune response. Cells were cultured in DMEM low glucose with $2 \mathrm{mM}$ glutamine and $10 \%$ FBS and passaged at 60-70\% confluence in T175 cell culture flasks (Nunc GmbH, Wiesbaden, Germany).

\section{Cell biology assessments}

\section{Plating efficiency after $\mathbf{2}$ hrs and metabolic activity after 3 days of HAC cultures}

The plating efficiency of chondrocytes was measured on native, POPE- and POPC-covered surfaces for both culture substrates ( 3 samples each). $2 \times 10^{5}$ cells $/ 50 \mu \mathrm{L}$ were applied onto the metallic samples as described. Aliquots of the same cell suspension were used for control DNA measurements.

Plating efficiency was assessed after 2 hours by measuring the DNA-content of the papain-digested supernatants. The values are given as mean percentages of the control (= seeded cell number) DNA-content, derived from 3 replicates per culture substrate.

The ongoing metabolic activity of chondrocytes cultured on the native and POPE-covered samples was analysed by the MTT-assay after three days of incubation, performing nine replicates per culture substrate.

\section{Proliferation of HAC after 11 days, and of HMSC after 5 days}

The proliferation of HAC was assessed by DNAmeasurements (6 replicates each). $2.5 \times 10^{5}$ cells $/ 50 \mu \mathrm{L}$ were seeded onto both growth substrates (native, POPEand POPC-covered) and cultured in DMEM $+10 \%$ FBS without further supplementation with medium change every other day for 11 days. The incubation time of 11 days was chosen because the protocol for HAC differentiation (see below) required this period of proliferation time before switching to differentiation conditions.

The proliferation of HMSC was analysed by seeding 2 $\mathrm{x} 10^{5}$ cells $/ 50 \mu \mathrm{L}$ on the native, POPE and POPC-covered porous metallic samples (same culture medium as above). It was assessed after 5 days by DNA-measurements (6 replicates each). This shorter incubation time was chosen because the proliferation behaviour of HMSC differs from HAC leading to confluent layers already after 7 days.

The respective cell morphologies on the growth substrates was visualised by low-voltage scanning electron microscopy (LVSEM).

\section{Determinations of chondrogenic potential, and of osteogenic potential after 21 days of culture-medium stimulation}

The chondrogenic potential of HAC was assessed by seeding $5 \times 10^{5}$ cells $/ 50 \mu \mathrm{L}$ on all metallic culture substrates. For proliferation they were first cultured for 11 days in DMEM with $10 \% \mathrm{FBS}$ and $10 \mathrm{ng} / \mathrm{mL}$ basic fibroblast growth factor. This was followed by incubation for 21 days in DMEM with $10 \%$ human serum (PAA Laboratories, Linz, Austria), $0.28 \mathrm{mM}$ L-ascorbic-acid-2-phosphate (AsAP; Sigma-Aldrich Cemie, Taufkirchen, Germany), 10 mM L-cysteine (Merck, Darmstadt, Germany), 100 ng/ $\mathrm{mL}$ insulin-like growth factor I (IGF-I), $10 \mathrm{ng} / \mathrm{mL}$ transforming growth factor $\beta 1$ (TGF- $\beta 1$ ) and $10 \mathrm{ng} / \mathrm{mL}$ Interleukin-4 (IL-4; R\&D-Systems, Wiesbaden, Germany) to switch the cells to the differentiated state. After 32 days chondroitin sulphate-(CS) and DNA-contents were 
determined as described below. On six independent replicate cultures, CS and DNA were measured three times from each sample (18 measurements in total per culture substrate and parameter).

$\operatorname{HMSC}\left(2 \times 10^{5}\right.$ cells/ $\left.50 \mu \mathrm{L}\right)$ were seeded on the porous Ti-6Al-4V specimen and incubated for 7 days (growth medium as described above). Then the osteogenic potential of HMSC after differentiation to bone forming cells was assessed by culturing in an osteogenic medium for 21 days (10 mM $\beta$-glycerol-phosphate, $5 \mathrm{mM} \mathrm{AsAP,} 10^{-7} \mathrm{M}$ dexamethasone and $10^{-7} \mathrm{M} 1 \alpha, 25$-dihydroxy-vitamin D3; Sigma-Aldrich-Chemie, Taufkirchen, Germany). This experiment was performed with three independent replicates (native and POPE covered porous Ti-6Al-4V). The osteogenic potential of the resulting cultures was analysed by RT-PCR and immunostaining of osteocalcin.

\section{Macrophage responses}

In order to evaluate a possible activation of macrophages caused by the phospholipids-coverings the macrophage reaction of the mouse cell line RAW 264.7 was tested in two ways.

First, phospholipid vesicles were prepared by dissolving $5 \mathrm{mg}$ of the 4 phospolipids (POPE, POPC, POPS and POPG, respectively) in a methanol/chloroform $(1 / 2$, by volume) solution. Subsequently, the solvent was removed slowly under a constant stream of nitrogen leading to the formation of a phospholipid multilayer film on the walls of the glass culture vials, which was dried overnight at $40^{\circ} \mathrm{C}$ in a vacuum oven. Then the phospholipid films were hydrated in $10 \mathrm{mM}$ sodium phosphate buffer, $\mathrm{pH} 7.4$ with a final concentration of 25 $\mathrm{mg} / \mathrm{mL}$ and added to the macrophage cultures $\left(1 \times 10^{4}\right.$ cells per assay on tissue culture plastic (TCP)) leading to a final phospholipid concentration in the growth medium of $625 \mu \mathrm{g} / \mathrm{mL}$. Lipopolysaccharide (LPS), a bacterial endotoxin, which is a potent inducer of nitric oxide synthase (NOS-2) production (Regunathan and Piletz, 2003) (10 ng/mL in distilled water; Sigma-Aldrich Chemie, Taufkirchen, Germany) was added to the RAW 264.7 cells as positive control, cells on TCP served as negative control. The mixtures were incubated in $2 \mathrm{~mL}$ medium for 48 hours (three replicate cultures). Then, the supernatant was filtered with a $0.22 \mu \mathrm{m}$ sterile filter to remove floating cells and remnants of the liposomes, and analysed with respect to NO content in the medium (two measurements per replicate, making 6 measurements per tested phospholipid and controls).

In the second experiment $5 \times 10^{3}$ macrophages per well were incubated, for two days, in 96-well plastic cell culture plates covered with the phospholipids POPE, POPC, POPS and POPG (8 replicates each). As a positive control, again LPS diluted in medium $(10 \mu \mathrm{g} / \mathrm{mL}$; Sigma-Aldrich Chemie, Taufkirchen, Germany), was chosen. The uncovered tissue culture plate in lipid-free medium served as a negative control. Cell viability was measured by MTT and immune response by the content of NO in the medium.

\section{Morphological and biochemical analyses}

\section{Low Voltage Scanning Electron Microscopy (LVSEM)}

To show surface topography and the cultured cells, as well as to identify the inorganic supporting material, low acceleration voltage scanning electron microscopy (LVSEM) was applied.

For conventional SEM, using acceleration voltages of $5 \mathrm{kV}$ and higher, a self-conductive or conductive-coated sample is needed. The result is the well known topographic image in secondary electron (SE) contrast. Compositional contrast in the backscattering mode (BSE) also needs high acceleration voltages. For thin organic structures, this results in transparent and not sharp images because of the large interaction volume for conventional SEM at high accelerating voltages and an escape depth in the order of half the penetration depth of primary electrons for the backscattered electrons.

LVSEM is a well known method for the investigation of fine structured polymers, blends and block copolymers (Butler et al., 1995). At very low accelerating voltages for non-conductive samples the escape depth for SE is in the same order as the penetration depth of the incident electron beam. The result is a reduced build-up of surface electron charge. The specific yield of SE emission for the different material compounds of the investigated surface leads to a compositional contrast in the SE-mode which lets the biological, carbon-containing material appear dark against inorganic parts of the specimen.

The cell-incubated samples were prepared for LVSEM by fixation in $2.5 \%$ glutaraldehyde (Sigma-Aldrich Chemie, Steinheim, Germany) overnight, and postfixed in osmium tetroxide $(1 \%$, dissolved in distilled water; Sigma-Aldrich Chemie, Steinheim, Germany) for $30 \mathrm{~min}$. Afterwards, the probes were dehydrated in a graded isopropanol series $(20 \%, 40 \%, 60 \%, 80 \%$ and $100 \%)$ respectively for 1 hour in each concentration. All steps were performed at room temperature. Samples were critical point dried (Baltec CPD 030, Balzers, Liechtenstein), and examined without conductive coating, using a Leo Gemini 1550 VP (LEO Elektronenmikroskopie GmbH, Oberkochen, Germany) with a SE1detector, at $0.3 \mathrm{kV}$.

\section{Quantitative analyses of DNA and chondroitin sulphate}

For quantification of DNA (= measure of cell number), and of chondroitin sulphate $(\mathrm{CS},=$ measure for glycosaminoglycans of the matrix), the respective cultures on the growth substrates were washed twice with phosphate-buffered saline (PBS) to remove non-adherent cells. The remaining cells were digested overnight in papain-solution $(10 \mathrm{mg} / \mathrm{mL}$ papain, Boehringer Mannheim $\mathrm{GmbH}$, Mannheim, Germany; $5 \mu \mathrm{L}$ mercaptoethanol in $0.1 \mathrm{M} \mathrm{NaH}_{2} \mathrm{PO}_{4}$, VWR International GmbH, Darmstadt, Germany) at $60^{\circ} \mathrm{C}$.

The DNA content of the supernatant from HAC and HMSC cultures was measured fluorometrically by incubation with $2 \mathrm{M} \mathrm{NaCl}, 15 \mathrm{mM}$ sodium citrate and 1 
$\mu \mathrm{g} / \mathrm{mL}$ bisbenzimide (Hoechst 33528; Serva Feinbiochemica GmbH \& Co., Heidelberg, Germany) for 15 minutes in the dark. Excitation wavelength was 355 $\mathrm{nm}$, and emission was measured at $460 \mathrm{~nm}$. The quantification was done with a calibration curve of 250 ng/mL standard DNA (Labarca and Paigen, 1980).

The CS content analysis was done by incubation of the digested probes with 1-9-dimethyl-methylen-bluechloride (Serva Feinbiochemica GmbH \& Co., Heidelberg, Germany) for $30 \mathrm{~s}$. The resulting colorimetric reaction was quantified by measuring the absorbance at $530 \mathrm{~nm}$ (Type 1420 Multilabel Counter, Wallac Distribution $\mathrm{GmbH}$, Freiburg, Germany) and determined by plotting against the calibration curve of $500 \mu \mathrm{g} / \mathrm{mL}$ shark chondroitin sulphate (Freed et al., 1999).

\section{MTT-assay for viability by metabolic activity of HAC and macrophage cultures}

The determination of the metabolic activity for HAC and macrophages was used to compare the initial adhesion on the different growth substrates after 2 hours with the measurement of cell viability after three days. Metabolic activity was determined by the "Cell Proliferation Kit MTT" (Roche Diagnostics GmbH, Mannheim, Germany). The MTT-assay is based on the cleavage of the yellow tetrazolium salt MTT (thiazolyl blue tetrazolium bromide) into purple formazan by metabolically active cells. $2 \times 10^{5}$ chondrocytes in $1 \mathrm{~mL}$ DMEM were cultured on native and POPE-covered growth substrates for three days. Then, the growth substrates were washed twice in PBS and $100 \mu \mathrm{L}$ of the MTT-solution $(5 \mathrm{mg} / \mathrm{mL}$ in PBS) was added. After an incubation period of 4 hours the cells were lysed and the formazan crystals solubilized by adding $1 \mathrm{~mL}$ solubilization solution ( $10 \% \mathrm{SDS}$ in $0.01 \mathrm{M} \mathrm{HCl})$ followed by an overnight incubation in a humidified atmosphere $\left(37^{\circ} \mathrm{C}, 5 \% \mathrm{CO}_{2}\right)$. The absorption of the solubilized formazan product was quantified photometrically using an ELISA reader (Tecan Sunrise, TECAN Deutschland $\mathrm{GmbH}$, Crailsheim, Germany) at $570 \mathrm{~nm}$ (with a reference wavelength of $655 \mathrm{~nm}$ ).

The protocol was adjusted for the macrophage cultures in native and phospholipid-covered 96-well plates. $1 \times 10^{3}$ macrophages in $100 \mu \mathrm{L}$ DMEM per well were cultured for only two days. The protocol was used as described with the addition of only $10 \mu \mathrm{L}$ MTT solution and $100 \mu \mathrm{L}$ of solubilization solution per well.

\section{DAPI staining}

To visualize all vital chondrocytes on the porous Ti-6Al$4 \mathrm{~V}$ cuboids they were stained with DAPI (4-6-Diamidino2-phenylindol-di-hydrochloride; VWR International, Darmstadt, Germany) after three days of incubation. Medium was removed and the growth substrates were washed with PBS. DAPI-solution $(1 \mu \mathrm{g} / \mathrm{mL}$ in methanol) was added and the specimens were incubated at $37^{\circ} \mathrm{C}$ for $15 \mathrm{~min}$ and left in the dark overnight at room temperature. Imaging was performed at 10-fold magnification using an Improvision Imaging System (Heidelberg, Germany) built around an epifluorescence microscope (Leica CTRMIC, Leica Camera AG, Solms, Germany). The sample was illuminated at $460 \mathrm{~nm}$ using a monochromator system (Polychromator IV, TILL Photonics, Graefelfing, Germany) and images were taken with a grey-scale CCD camera (type C4742-95-12ER; Hamamatsu, Enfield, UK) operated in 12 bit mode. Colours were implemented offline using the Openlab Imaging software module (Improvision, Heidelberg, Germany).

\section{Osteocalcin immunostaining}

The fluorescent staining of osteocalcin was performed to visualise the osteogenic differentiation of HMSC as described by Cowan et al. (2003). After the differentiation period, the samples were washed with PBS and fixed for $10 \mathrm{~min}$ in $3.7 \%$ formaldehyde (Sigma-Aldrich Chemie, Taufkirchen, Germany) at room temperature. Then, cells were permeabilized by $0.5 \%$ Triton-X (Sigma-Aldrich Chemie, Taufkirchen, Germany) for 10 minutes and unspecific antibody reactions were blocked in $1 \%$ Triton/ $2 \%$ BSA (Fluka, Taufkirchen, Germany). The primary antibody (monoclonal anti-osteocalcin clone OC1; Abcam, Cambridge, UK) was applied for 1 hour at $37^{\circ} \mathrm{C}$. After two washings with PBS the secondary antibody (goat antimouse IgG FITC in PBS / BSA; Chemicon International, Ltd., Hofheim, Germany) was applied, followed by two rinses in PBS. Prior to the imaging the stained samples were incubated over night at $4^{\circ} \mathrm{C}$. Imaging was performed as described above.

\section{Total RNA extraction and complementary DNA synthesis}

RNA as a template for the cDNA synthesis was extracted using the High Pure RNA Isolation Kit (Roche Diagnostics $\mathrm{GmbH}$, Mannheim, Germany). In brief, cell pellets were resuspended in PBS; lysis-buffer was added on the filtertube and the solution centrifuged for $15 \mathrm{~s}$ at $8000 \mathrm{~g}$. For cleaning, $10 \mu \mathrm{L}$ DNAse I in incubation buffer was added and incubated for $15 \mathrm{~min}$ at room temperature. After three washing steps of the lysate, RNA was eluted by centrifugation ( $1 \mathrm{~min}$ at $8000 \mathrm{~g}$ ) in elution buffer. Complementary DNA (cDNA) was generated using the Omniscript reverse transcriptase for first strand cDNA synthesis kit (Qiagen GmbH, Hilden, Germany) with 1 $\mu \mathrm{m}$ Oligo-dt primer and 4 units/reaction Omniscript reverse transcriptase in the presence of dNTPs. The integrity of the preparations was controlled on a $1 \%$ agarose/ ethidiumbromide gel.

\section{Reverse transcriptase-polymerase chain reaction (RT-PCR) for bone cell protein genes expression}

To determine the gene expression patterns for certain typical bone cell proteins on the different substrate materials, PCR reactions were performed using the Eppendorf Mastercycler gradient (Eppendorf AG, Hamburg, Germany). The PCR master mix was based on platinum Taq DNA Polymerase (Invitrogen Corporation, Karlsruhe, Germany). CDNA-samples $(5 \mu \mathrm{L}$ per $25 \mu \mathrm{L}$ reaction) were analysed for the genes of interest. As reference (= housekeeping) gene, GAPDH was used (abbreviated GAP in figure 8). The analysed genes and primers were: 

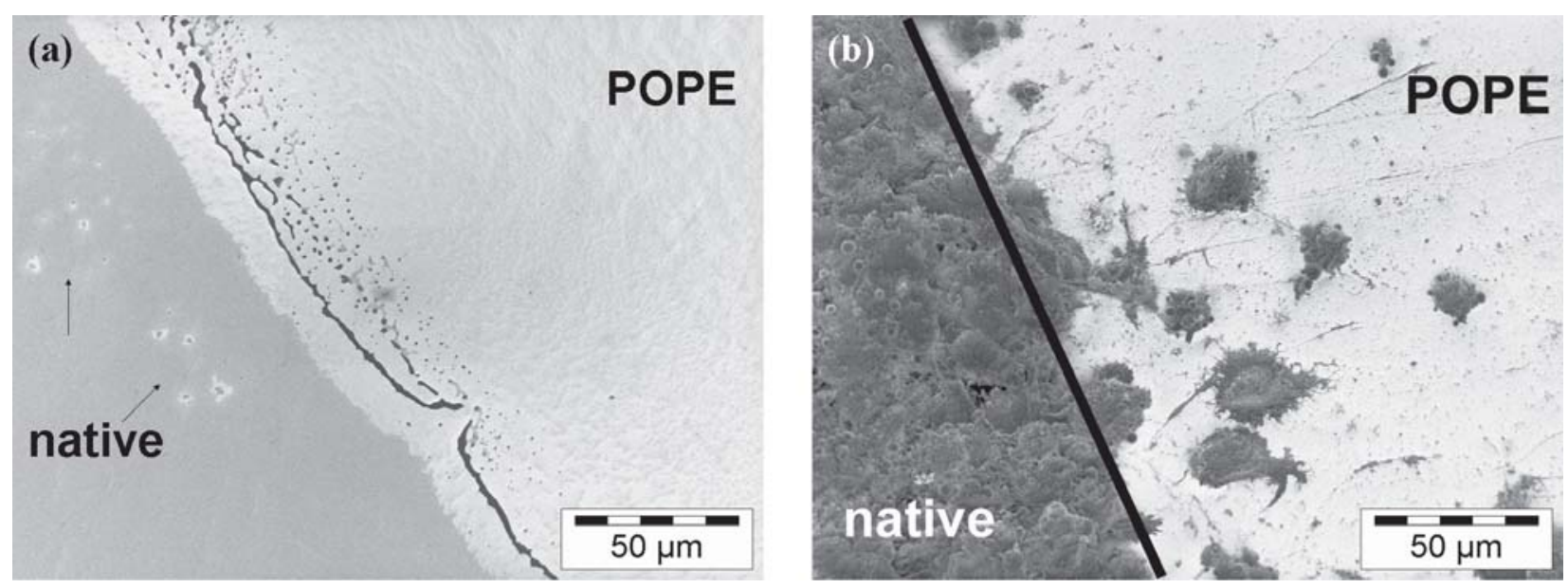

Figure 1. Low voltage field emission SEM-micrographs of mirror-like polished, only partially POPE-covered Ti$6 \mathrm{Al}-7 \mathrm{Nb}$ discs. (a) The borderline between the native surface (grey) and the phospholipid-covered part (white) is clearly visible. The black lines in the lipid coated area mark thick lipid regimes. The arrows indicate lipid droplets on the uncovered growth substrate. (b) Human articular chondrocyte (HAC) attachment after 2 hours. Note the high density of rounded cells on the native side of the disc, while only single rounded cells attached on the POPE-covered area of the specimen.

alkaline phosphatase (ALP):

for 5'-ACGTGGCTAAGAATGTCATC-3', rev 5'CTGGTAGGCGATGTCCTTA-3';

osteocalcin (OC):

for 5'-CATGAGAGCCCTCACA-3', rev 5' AGAGCGACACCCTAGAC-3';

osteopontin (OPN):

for 5'-CCAAGTAAGTCCAACGAAAG-3', rev 5'GGTGATGTCCTCGTCTGTA-3';

core binding factor alpha 1 (cbfa1):

for 5'-CCCCACGACAACCGCACC-3', rev 5' CACTCCGGCCCACAAATCTC-3';

and collagen type $\mathrm{I}(\mathrm{CI})$ :

for 5'-TGACGAGACCAAGAACTG-3', rev 5'CCATCCAAACCACTGAAACC-3'; they were taken from Kamata et al. (2004).

The preparations were visualized on a $1 \%$ agarose/ ethidium-bromide gel.

\section{Nitric oxide (NO)-measurements}

The production of nitric oxide by macrophages is induced by stimulators of the immune response, e.g. LPS (Regunathan and Piletz, 2003). The assessment of nitric oxide was done by the measurement of $\mathrm{NO}_{2}$ in the medium. An aliquot of the medium $(100 \mu \mathrm{L})$ was mixed with $50 \mu \mathrm{L}$ of Griess reagent (Fluka, Taufkirchen, Germany), incubated for 5 minutes at room temperature. Then the absorbance at $542 \mathrm{~nm}$ was determined. Solutions of sodium nitrite $\left(\mathrm{NaNO}_{2}\right)$ (Sigma Aldrich Chemie, Taufkirchen, Germany) diluted in DMEM served as standards.

\section{Statistical Analyses}

Statistics were performed using the SigmaStat package (Systat Software GmbH, Erkrath, Germany). The comparison between two groups of samples was performed using the Student's $t$-test. Standard analysis comparing more than two treatments was done by using One-way ANOVA. Depending on the data distribution either a oneway ANOVA or an ANOVA on ranks was performed. Post hoc tests were Holm-Sidak or Dunn's versus the control groups, respectively. Statistical significances are indicated in the respective experimental results, tables and figure legends.

\section{Results}

\section{Cell adhesion, morphology and matrix production of HAC}

As a proof of principle, the initial tests were performed with HAC. Chondrocyte adhesion was first analyzed on mirror-like polished Ti-6Al-7Nb growth substrates. In order to visualize a comparison between phospholipid covered and uncovered surfaces, only half of the disc was dipped into the POPE solution (see Figure1a) before

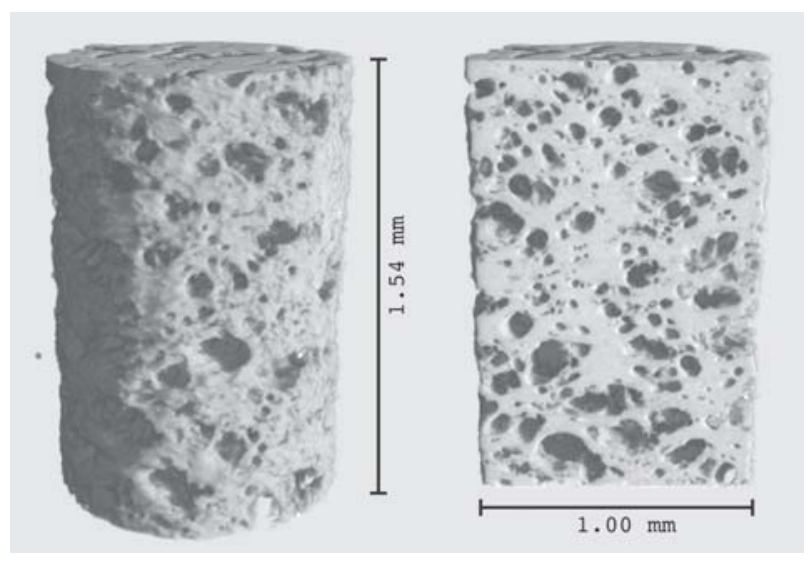

Figure 2. 3D-reconstruction images of the porous Ti$6 \mathrm{Al}-4 \mathrm{~V}$ material (720 projections of X-ray microtomography $(\mu \mathrm{CT})$ images, recorded under varying angles at an X-ray photon energy of $33 \mathrm{keV}$ ). From these data an average of $34.4 \%$ non-connected, randomly distributed outer (= surface) and inner porosity was calculated, the pore sizes ranging between 10 and $200 \mu \mathrm{m}$. 
Table 1. Matrix production (CS-content) and cell number (DNA-content) of HAC after 3 weeks under chondrogenic conditions on mirror-like polished and porous growth substrates without/with POPE-coating. Content values are means \pm standard deviation. On POPE-covered mirror polished Ti-6Al-7Nb discs the ratio CS/DNA is $30.6 \%$ higher than on the native material, while for the POPE-covered porous Ti-6Al-4V material the ratio is $26.7 \%$ higher. Significance levels are indicated by asterisks $(*=p<0.05 ; * * *=p<0.001)$.

\begin{tabular}{|c|c|c|c|c|c|c|}
\hline & \multicolumn{5}{|c|}{ HAC } & \multirow[b]{2}{*}{$\Delta \%$} \\
\hline Material & $\mathrm{CS}[\mu \mathrm{g}]$ & $\Delta \%$ & DNA $[\mu \mathrm{g}]$ & $\Delta \%$ & CS/DNA & \\
\hline $\begin{array}{l}\text { Polished } \\
\text { Ti-6Al-7Nb }\end{array}$ & $53.11 \pm 11.03$ & & $13.79 \pm 1.68$ & & 3.85 & \\
\hline $\begin{array}{c}\text { Polished } \\
\text { Ti-6Al-7Nb } \\
+ \text { POPE }\end{array}$ & $36.46 \pm 4.35$ & $-31.35 \%$ & $7.25 \pm 0.59$ & $-47.43 \%$ & 5.03 & $\begin{array}{c}+30.58 \% \\
* * * \\
\end{array}$ \\
\hline $\begin{array}{c}\text { Porous } \\
\text { Ti-6Al-4V }\end{array}$ & $76.01 \pm 22.94$ & & $11.21 \pm 1.40$ & & 6.78 & \\
\hline $\begin{array}{c}\text { Porous } \\
\text { Ti-6Al-4V } \\
+ \text { POPE }\end{array}$ & $100.57 \pm 11.22$ & $+32.31 \%$ & $11.71 \pm 1.93$ & $+4.46 \%$ & 8.59 & $\begin{array}{c}+26.66 \% \\
*\end{array}$ \\
\hline
\end{tabular}

incubation with chondrocytes. After $2 \mathrm{hrs}$ incubation (see Figure 1b), a severe difference was found. All adhering cells showed a rounded morphology, but on the POPEcovered area only very few spreading-out cells were detected, while on the native metallic surface a dense cell population started to grow on each other.

In order to show, if this effect of phospholipid-coating is also metallic surface structure related, the porous substrates (see Figure 2) were used for the following experiments. After 3 days of incubation on native porous Ti-6Al-4V surfaces all adhering chondrocytes showed a flattened, elongated morphology (Figure 3a), resembling the fibroblastic phenotype. On the POPE covered porous surfaces, however, the major part of chondrocytes developed a more rounded shape (Figure $3 b$ ). While the cells tend to accumulate on the surfaces and did not invade the cavities of the native alloy (Figure 3a, left upper corner and Figure 4a), the cells tend to inhabit mainly the pores and not the surfaces, if the porous metallic surface is POPEcovered (Figure 4b).

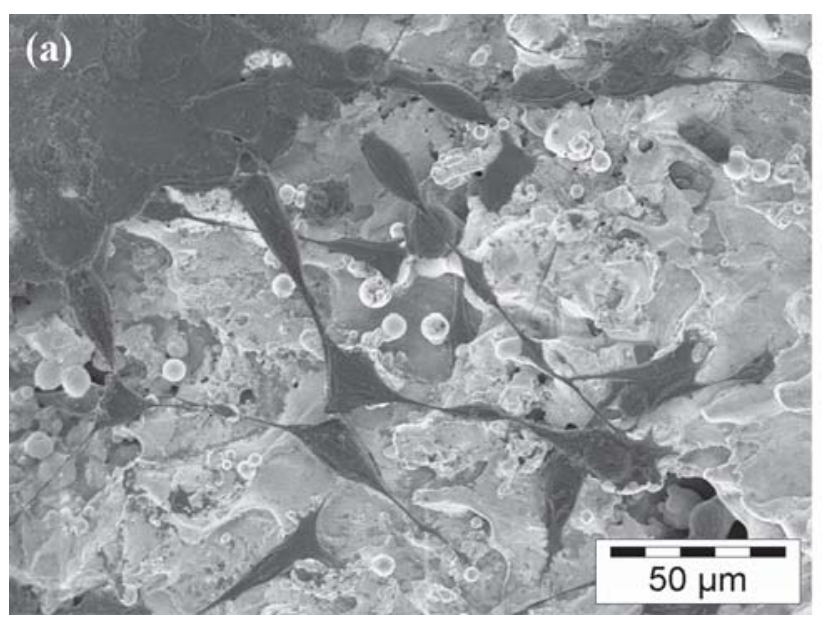

To establish a time course between initial chondrocyte adhesion, further survival, and cell differentiation, the adhesion after 2 hours, and the metabolic activity of the cells after three days were analyzed on polished and on porous substrates. Again, on the POPE-covered smooth mirror-like polished Ti-6Al-7Nb surface only $42 \%$ of the seeded cells adhered (in comparison to $99 \%$ on the native polished Ti-6Al-7Nb), while the initial adhesion was high on the POPE-covered porous Ti6Al4V surfaces ( $99 \%$ of the seeded cells, compared to only $83 \%$ on native surfaces) (Figure 5a). Thus, interestingly the POPE-coating on the porous surface led to an increase in adherent cells $(116 \%$ in comparison to the cell number of the uncovered sample). The metabolic activity measured after three days (Figure $5 b)$ showed that on the POPE- covered mirror-like polished Ti-6Al-7Nb surface a significantly lower MTT-value $(t=$ $5.677, n=9, p<0.005)$ as compared to the native metallic surface was measured, whereas on the POPE covered porous growth substrates a significantly higher activity ( $t$ $=-7.32 ; n=9 ; p<0.001)$ was found.

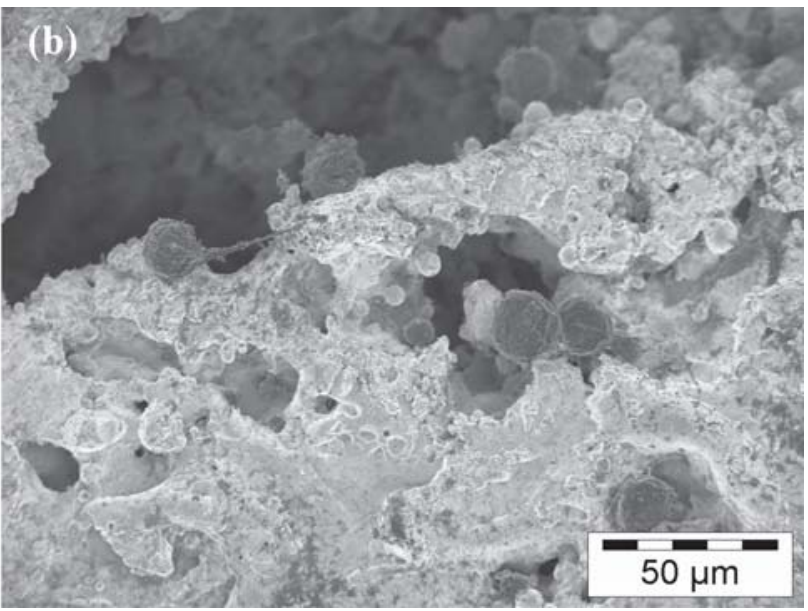

Figure 3. Comparison of HAC morphology after 3 days proliferation on native (a) and POPE-covered (b) porous Ti$6 \mathrm{Al}-4 \mathrm{~V}$, detected by low voltage field emission SEM. On the native growth substrate most cells show a fibroblastlike phenotype (a), while the cells in the pores of POPE-covered surface exhibit a round chondrocyte-like morphology (b). 

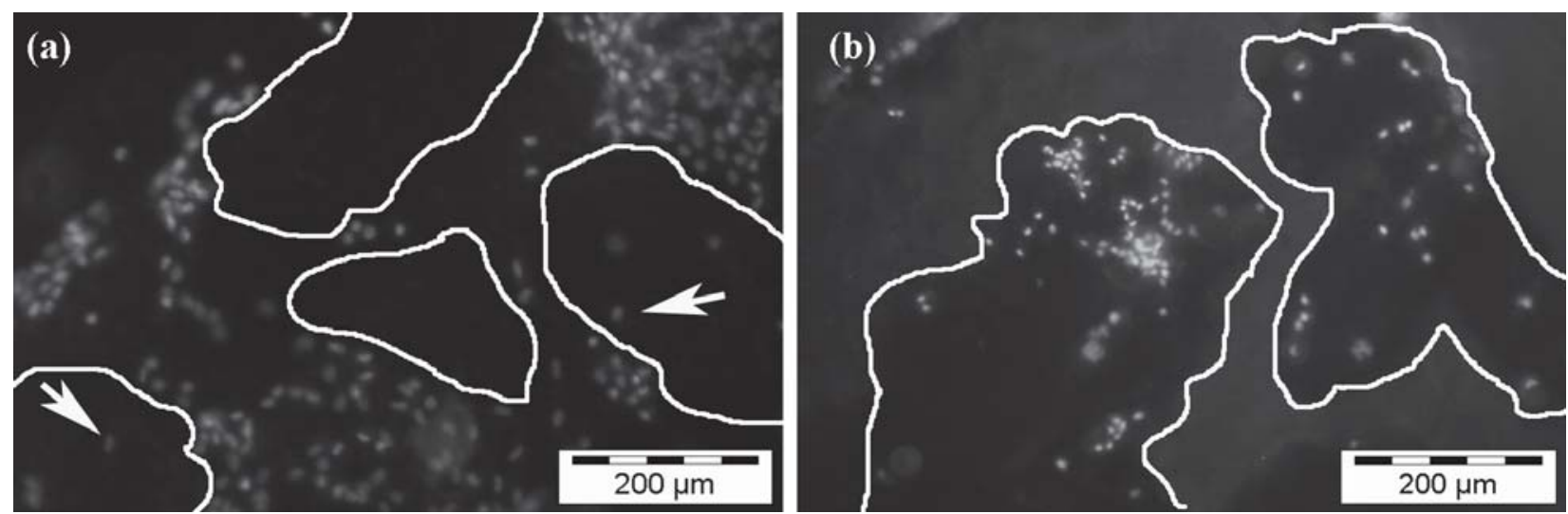

Figure 4. Adhesion and survival of HAC on the porous Ti-6Al-4V cuboids after 3 days (Fluorescence microscopy (magnification 400x) of DAPI-immunostained cells). (a) Most HAC adhered on the flat surfaces of the native material, only few cells (arrows) can be recognized within the pores, indicated by white outlines. (b) HAC on the POPE-covered material, showing less adherent cells, but mainly in the pores, indicated by white outlines. The bluish shades represent the flat surfaces of the porous material.

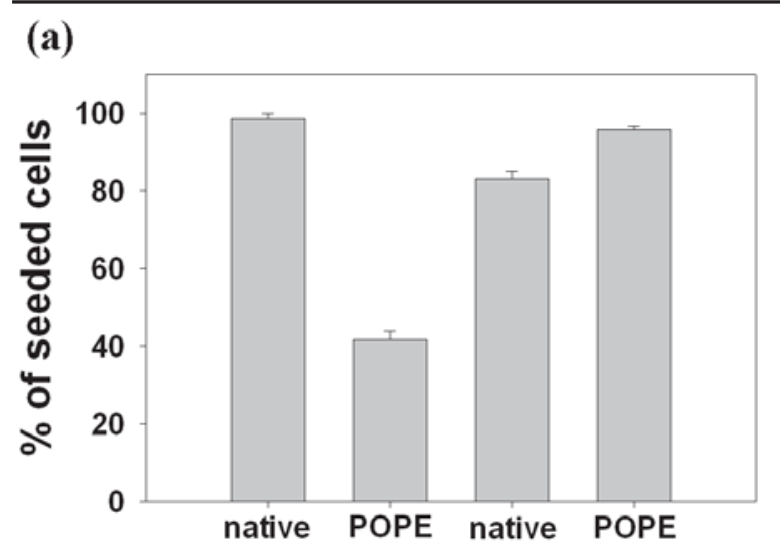

polished Ti-6Al-7Nb / porous Ti-6Al-4V

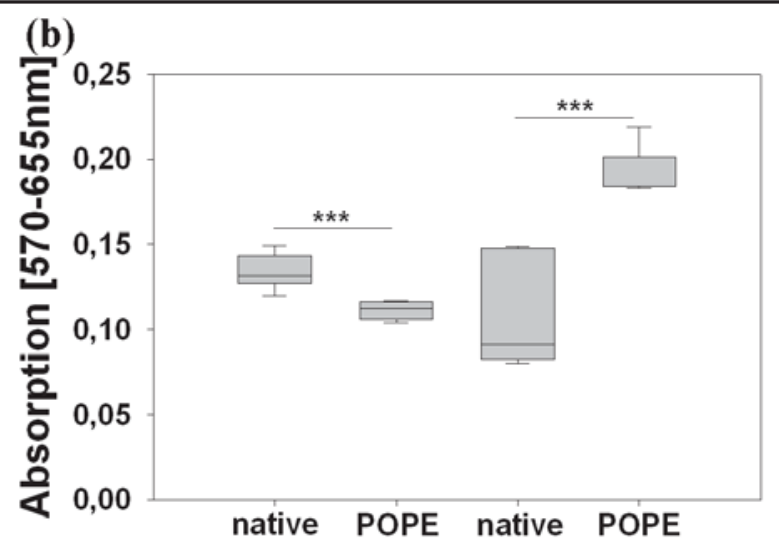

polished Ti-6Al-7Nb / porous Ti-6Al-4V

Figure 5. Influences of POPE-covering on HAC adhesion and metabolic activity on native and POPE-covered polished and porous growth substrates.

(a) Number of adhering HAC after 2 hours, given in \% of the DNA-measurement of initially seeded $2 \times 10^{5}$ cells. Mean values of 3 replicate cultures each.

(b) Metabolic activity of HAC, measured by MTT-assay after 3 days. Data from 9 replicate cultures are shown in box and whisker plots. Asterisks $(* * *)$ indicate statistically significant differences $(t$-test, $p<0.001)$; polished Ti$6 \mathrm{Al}-7 \mathrm{Nb}: t=5.677, n=9$; porous Ti-6Al-4V: $t=7.32, n=9$.

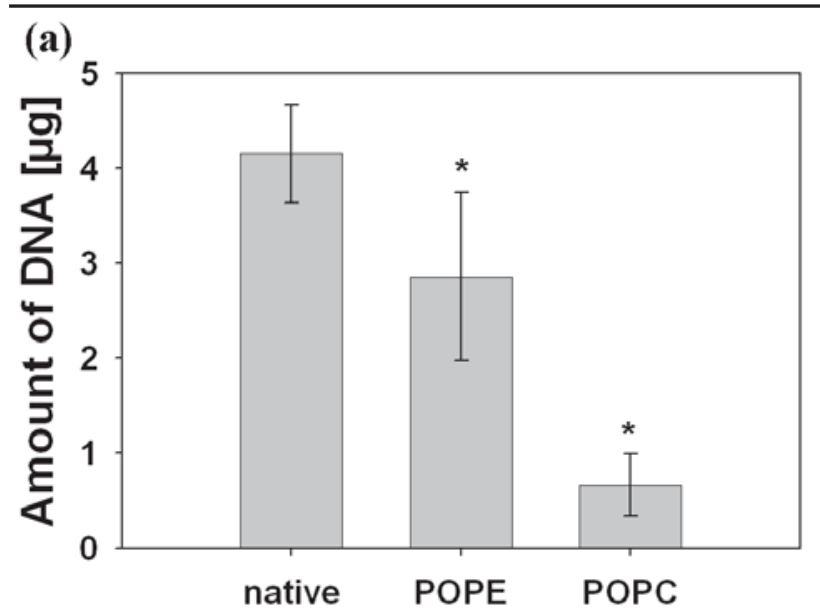

Polished Ti-6AI-7Nb-surfaces

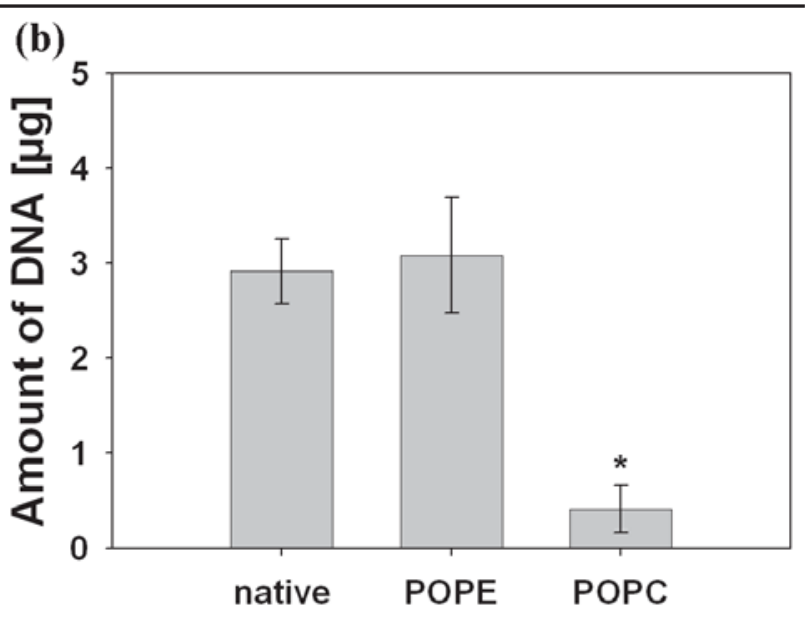

Porous Ti-6Al-4V-surfaces

Figure 6. Comparison of HAC proliferation after 11 days on POPE- and POPC- covered mirror-like polished Ti-6Al$7 \mathrm{Nb}$ discs (a) and porous Ti-6Al-4V cuboids (b) with respective native surfaces. Plotted are average DNA values and standard deviations from 6 replicate cultures each, seeded initially with $2.5 \times 10^{5}$ cells. Asterisks indicate significant differences $(p<0.05)$. 

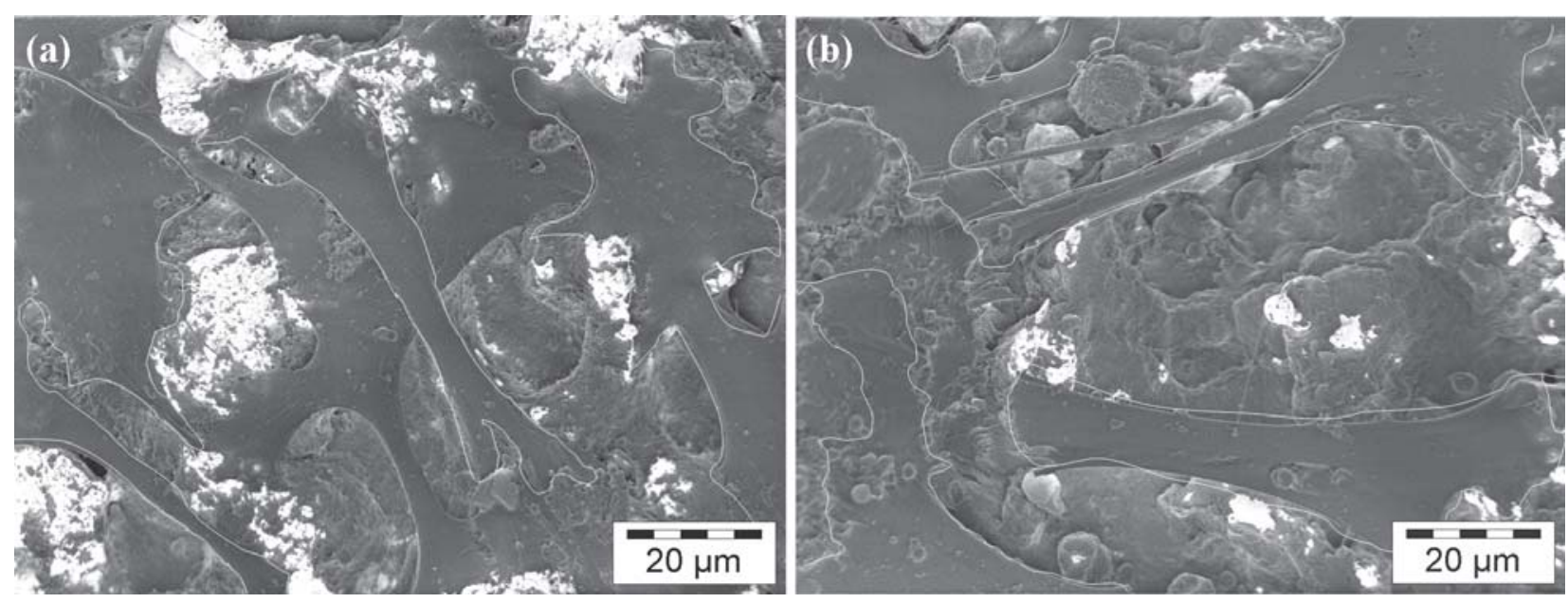

Figure 7. Human mesenchymal stem cells (HMSC), grown for 5 days on native (a) and POPE-covered (b) porous Ti-6Al-4V, shown by low voltage field emission SEM. The cells (some cell areas with white outlines) exhibit a long, wide spanning morphology on both surfaces.

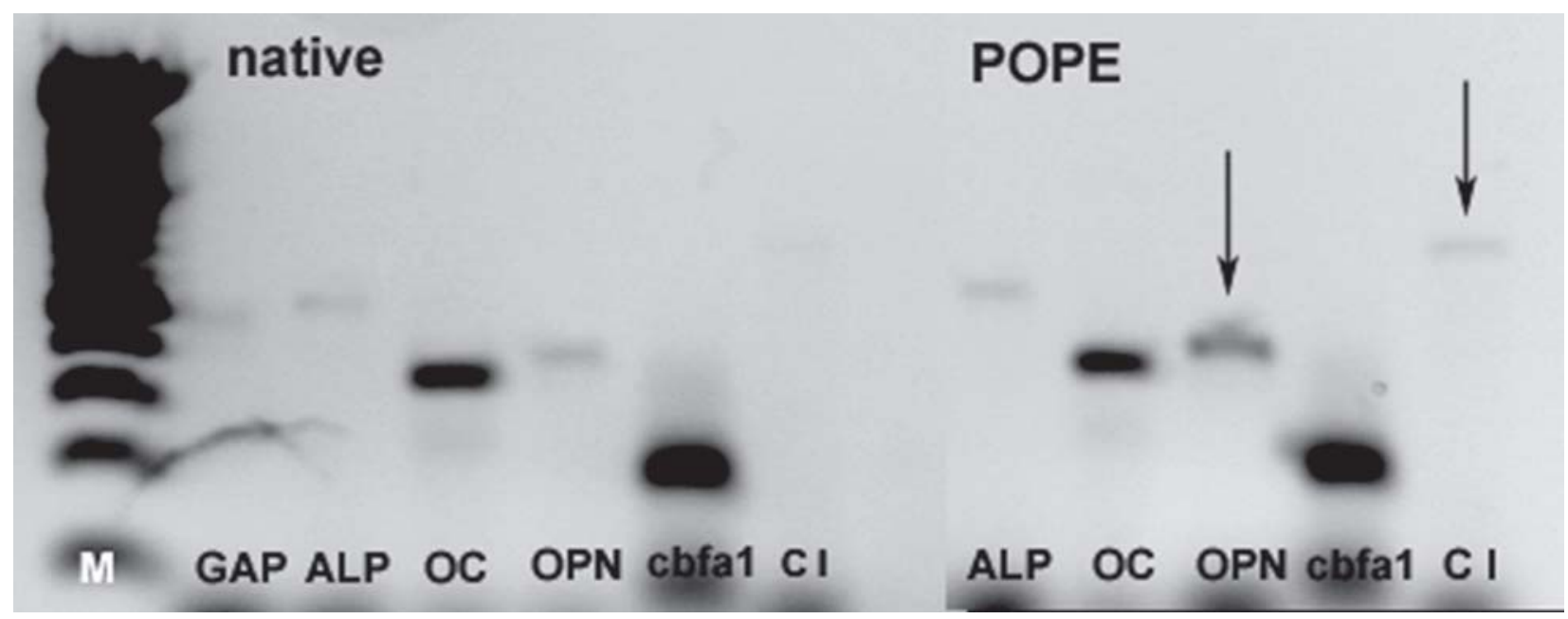

Figure 8. Gel-electrophoretic analysis of several protein encoding genes, produced by HMSC as relevant markers for osteogenic differentiation after 28 days on a native and POPE-covered porous Ti-6Al-4V surfaces. $\mathrm{M}=\mathrm{Marker}$ : DNA-Ladder, GAP = glyceraldehyde-3-phosphate dehydrogenase: housekeeping gene, ALP = Alkaline Phosphatase, $\mathrm{OC}=$ Osteocalcin, $\mathrm{OPN}=$ Osteopontin, $\mathrm{cbfa} 1=$ core binding factor alpha $1, \mathrm{C} \mathrm{I}=$ Collagen $\mathrm{I}$. Arrows indicate genes which were stronger expressed on the POPE-covered porous surface.
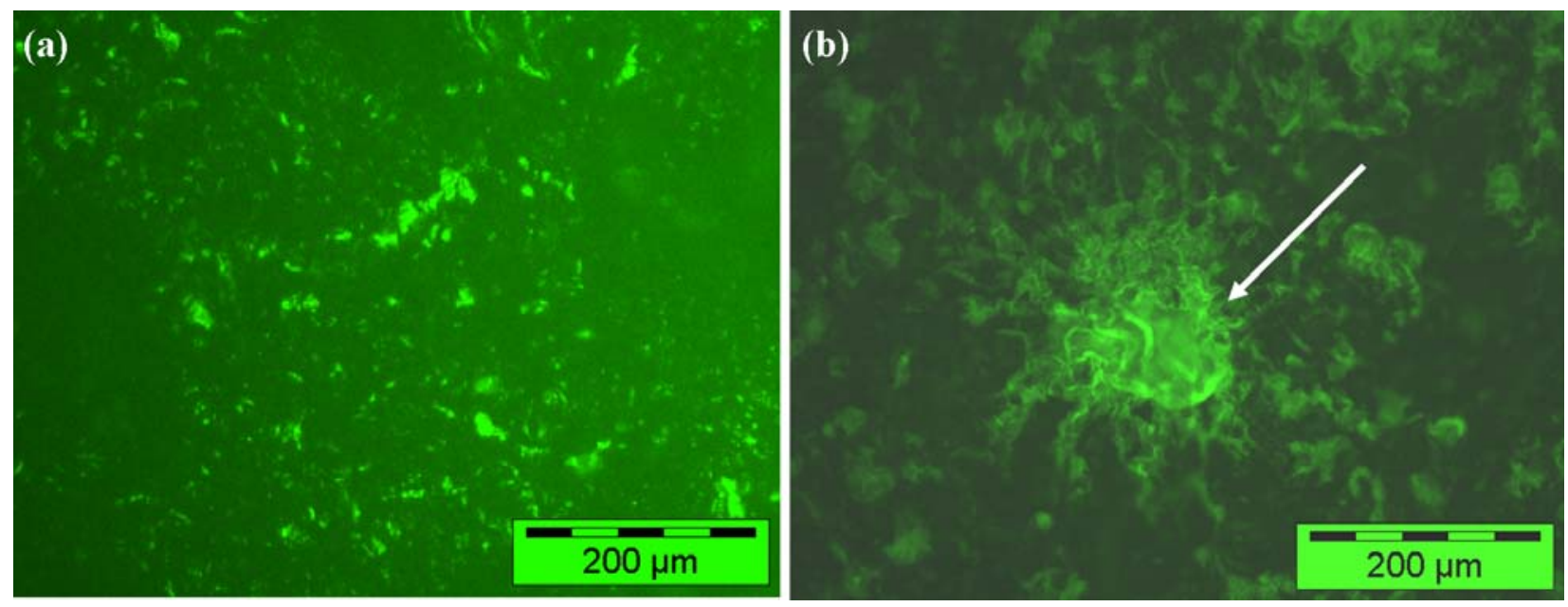

Figure 9. Bone nodule formation by HMSC after 28 days of osteogenic differentiation (Osteocalcin-FITC staining). (a) On native porous Ti-6Al-4V surfaces no bone nodules were detected. (b) In contrast, on the POPE-covered porous Ti-6Al-4V growth substrate bone nodules (arrow) were found. 


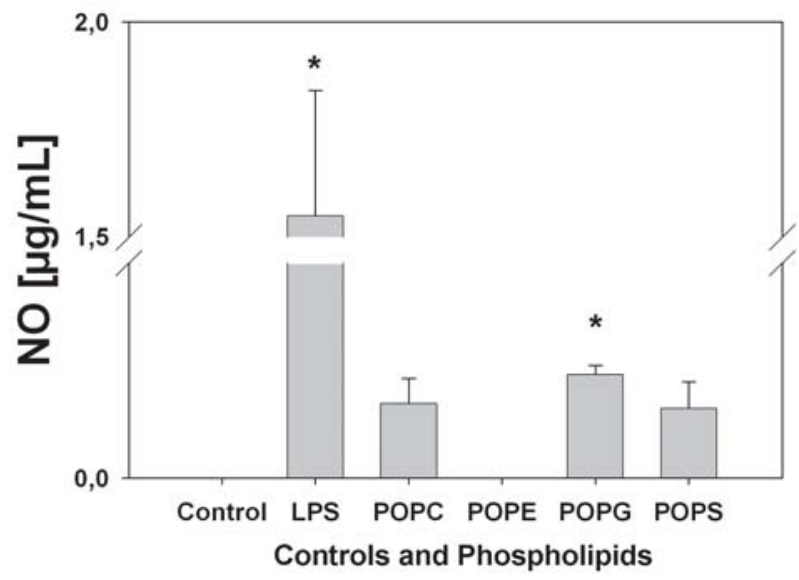

Figure 10. RAW 264.7 macrophage nitric oxide (NO) production, activated by various phospholipid vesicles in solution. As controls, lipopolysaccharide (LPS), a strong activator of immunogenic macrophage response, and culture well plastic, which should have no effect on NO production, were used. Significant differences (ANOVA) from the negative control are marked by asterisks $(p<0.05)$.

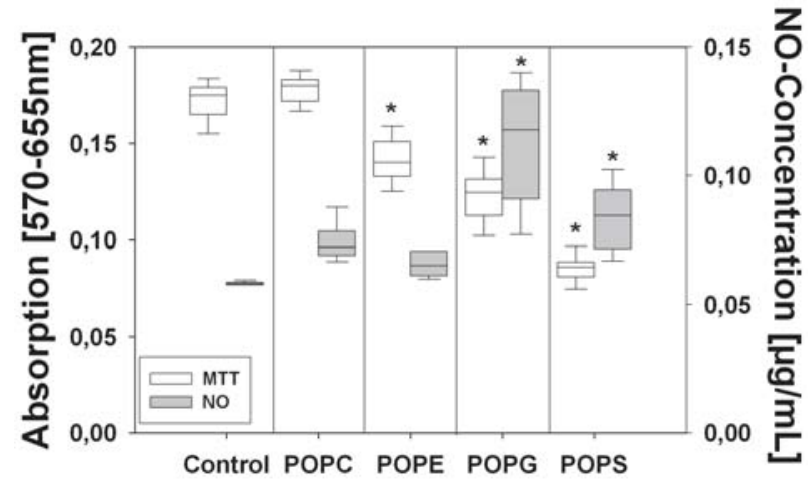

Figure 11. Macrophage viability and immunogenic activation by various phospholipids in culture, determined by metabolic activity (MTT) and the production of NO. As negative control, lipid free growth medium was used. As positive control, LPS $(10 \mu \mathrm{g} / \mathrm{mL}$; Sigma-Aldrich Chemie, Taufkirchen, Germany), diluted in medium, was chosen, but the induced amount of NO is not displayed here, because it was on average three times higher than for the phospholipids (see text). Significant differences to the negative control (ANOVA) are marked by asterisks $(p<0.05)$.
If we compare the adherent cell number with the viability, POPE increases the viability of the cells on both materials. While the ratio between adherent cells on the smooth uncovered to POPE covered surface is a factor of 0.42 , in comparison the corresponding MTT ratio increases to 0.83 . The same trend was observed on the porous surface. Here the ratio of adherent cells on the native and POPE covered growth substrate is 1.16 (in favour of the phospholipid-covered surface). The calculation of the corresponding MTT-ratios leads to a value of 1.8 (calculated from the average absorption values), indicating that the viability of adherent cells is again stimulated by this phospholipid-coating.

The analysis of cartilage matrix production by measuring the amount of chondroitin sulphate as a matrix compound with respect to the cell number showed that POPE-coating supports chondroitin sulphate production. When comparing mirror-like polished and porous material surfaces (see Table 1), the ratio of chondroitin sulphate (CS) per DNA is significantly higher by a factor of 1.3 for POPE-covered surfaces ( $t$-tests: CS/DNA $+30.58 \%$ on POPE-covered polished surfaces, $t=-4.17, n=6, p<$ $0.001 ; \mathrm{CS} / \mathrm{DNA}+26.66 \%$ on POPE-covered porous surfaces, $t=-2.675, n=6, p<0.05)$.

To determine whether the initially reduced cell numbers on phospholipids-covered smooth surfaces is due to a general repulsive phospholipid property, a comparison between the DNA content of HAC incubated for 11 days on native, POPE- and POPC-covered polished Ti-6Al-7Nb discs, respectively, was performed. It showed a significant DNA decrease for both phospholipids in relation to the uncovered controls. However, HAC attachment on POPC was even lower than for POPE. Only $17.9 \%$ of the initial cells were found on POPC $(t=9.74, n=6, p<0.05)$, while $68.9 \%$ were still present on $\mathrm{POPE}(t=3.612, n=6$, $p<0.05$; Figure 6a).
When HAC were also incubated for 11 days on native porous Ti-6Al-4V cuboids, and substrates covered with POPC and POPE, the number of cells was again significantly reduced on POPC-coatings $(14.3 \%$ of the control, $t=10.169, n=6, p<0.05)$, while on POPEcoatings an even higher number of cells was found as on native surfaces (Figure 6b).

\section{HMSC adhesion, morphology, proliferation and differentiation}

After having determined the positive influence of a porous phospholipid-covered metallic surface on the chondrocyte model system, the interaction of human mesenchymal stem cells (HMSC) was evaluated only on native and POPEcovered porous Ti-6Al-4V material. As it can be seen in Figure 7, the HMSC did not develop distinct differences in their morphology on either surface. The cell bodies are elongated and spread over large areas, their sizes being approximately the same on native and POPE-covered surfaces. Contrary to HAC, no clear invasion of the cells into the pores was detected. The proliferation in terms of the cell number (DNA seeded cells $=2.0+/-0.07 \mu \mathrm{g}$ ) increased by $70 \%$ on the native, and by $77 \%$ on the POPEcovered surface after three days of incubation (respective DNA-values: native $3.4+/-0.3 \mu \mathrm{g}$, POPE-covered $3.5+/$ - $0.2 \mu \mathrm{g} ; n=6$ ). This seems to indicate that POPE does not have a negative influence on HMSC proliferation.

As stated above proliferation alone gives an incomplete picture. Here, the HMSC were driven into the osteogenic pathway, and the osteogenic potential was tested on native and POPE-covered porous Ti-6Al-4V surfaces. All osteogenic markers were expressed on both surfaces. Visible differences were observed for the expression of osteopontin and collagen I (Figure 8). To determine whether these differences on the gene expression level are also observed on the protein expression level, a fluorescent 
staining of osteocalcin was performed. Although all gene markers were expressed also on the native surfaces, at this time point of differentiation, no bone nodule formation was observed in the immunofluorescence on the native carrier (Figure 9a). Contrary, on the POPE-covered porous surfaces first bone nodules were detected after three weeks of osteogenic differentiation (Figure 9b). This shows that the POPE-coating seems to have more impact on osteogenic stem cells differentiation.

\section{Macrophage interaction with phospholipid vesicles and phospholipid coatings}

One important assumption concerning the coating of a metal implant with phospholipids was that a surface is created which is not detected as foreign by defence cells. Among them are macrophages which can be tested easily. Measurements of RAW 264.7 macrophage-cultures in contact with phospholipid vesicles showed that POPEliposomes, like the plastic culture well surface, did not stimulate nitric oxide (NO) production, while values around $0.1 \mu \mathrm{g} / \mathrm{mL}$ NO were detected for the other three phospholipids (Figure 10). The most pronounced interaction was found for POPG $(0.1+/-0.01 \mu \mathrm{g} / \mathrm{mL} \mathrm{NO}$, $\mathrm{Q}=2.875, n=4, p<0.05)$, while POPS and POPC induce a lower NO-production (POPS $=0.07+/-0.02 \mu \mathrm{g} / \mathrm{mL}$, POPC $=0.07+/-0.02 \mu \mathrm{g} / \mathrm{mL})$. Still these concentrations were two orders of magnitude smaller than compared to LPS $(1.55+/-0.3 \mu \mathrm{g} / \mathrm{mL})$ which induces a significant activation of $\mathrm{NO}$ production $(\mathrm{Q}=4.417, n=6, p<0.05$; ANOVA on ranks, Dunn's post hoc test versus control).

On phospholipids-covered surfaces macrophagecultures showed in principle the same trend as for vesicle interaction. NO production was most pronounced for POPG $(\mathrm{Q}=4.375, n=10, p<0.05$; fig. 11). POPS $(\mathrm{Q}=$ $3.197, n=10, p<0.05)$ and POPC showed a weak NO activation, while for POPE the amount of NO was comparable to the control. If the cell viability is considered, POPC did not interfere with the cell metabolism which is comparable to the control. For POPE a reduction of the metabolic activity was measured $(t=5.03, n=10, p<$ $0.05)$. The negatively charged phospholipids POPG and POPS significantly reduced cell viability (POPG: $t=8.122$, $n=10, p<0.05$; POPS: $t=14.265, n=10, p<0.05)$. Thus, the cytocompatibility of the tested phospholipids showed the following ranking: $\mathrm{POPC}>\mathrm{POPE}>\mathrm{POPG}>$ POPS. The according values for LPS are not displayed because, as expected (Poltorak et al., 1998), at least for the NO-concentration they are significantly higher than for the phospholipids (MTT mean value: $\mathrm{A}_{570-655 \mathrm{~nm}}=0.177$, NO-concentration: $0.265 \mu \mathrm{g} / \mathrm{mL} ; \mathrm{Q}=5.616, n=10, p<$ $0.05)$.

\section{Discussion}

The aim of this study was to test the hypothesis that phospholipids play an important role for the interaction of cells with growth substrate. As known from previous studies the application of POPE leads to self-assembled multilamellar phospholipid bilayers (Willumeit et al., 2003a) with a similar contact angle as it was determined for the plasma membrane of e.g. osteoblasts (Zanchetta and Guezennec, 2001). Part of the phospholipid material is exfoliating upon incubation in water or growth medium, but still a significant amount of phospholipid bilayers stays on the titanium alloy substrate (Willumeit et al., 2003b; Willumeit et al., 2007). The mechanical characterisation of these phospholipid layers is very complicated, because none of the typical tests (peeling, fractioning etc.) will give reliable data. This is due to the liquid crystalline nature of the lipid film which will rearrange upon external forces and which is kept together by Van-der-Waals bonds and hydrophobic interactions. Furthermore, in the ideal case, we have to characterize a coating that is only several $\mathrm{nm}$ thick, a challenge that is not easily met. However, currently a thorough investigation of the layers by AFM and diffraction / reflectivity measurements is performed.

HAC cells were chosen as a model system, because it is well described, they are relatively easy to culture and show a different morphology dependent on their degree of differentiation (Abbott and Holtzer, 1966; Glowacki et al., 1983; Holtzer et al., 1960). If the phospholipid coating has an influence on cell attachment, proliferation and differentiation, this should be easy to monitor with HAC. The more realistic cells for skeletal implants are HMSC. Therefore, based on the experiences made with HAC, selected properties of HMSCs, mainly morphology and matrix production, were also evaluated.

Two phospholipids where chosen for the basic HAC studies: POPE, which is abundant in eukaryotic cells and has very interesting biophysical properties such as polymorphism which is a prerequisite for membrane fusion or cell division, and POPC as the negative control, because it is highly abundant in erythrocyte membranes and considered to be the important factor preventing aggregation of red blood cells (Hayward and Chapman, 1984).

The HAC attachment studies showed that only few cells attach on the phospholipid POPE covered mirror-polished metallic surfaces. This discouraging finding can be explained at least in two ways: First the cells do not adhere on the phospholipid in general because the coating has a repulsive effect as it is known for PC-headgroup phospholipids used to produce blood compatible coatings (Ishihara et al., 1992; Iwasaki et al., 1999; Iwasaki et al., 2001; Korematsu et al., 2002; Lewis et al., 2001; Smeets et al., 1996; Zwaal et al., 1998). On the other hand it might be speculated that the cells can adhere to phospholipid coatings, but are then washed away with the underlying phospholipid layer which is only loosely bound to the metallic surface by hydrophobic and charge effects. That the latter could be the case, in combination with specific phospholipid selectivity of the cells, was shown in cell attachment studies on porous Ti-6Al-4V surfaces where the phospholipid layers covered also the voids and tunnels of the material. Then, for POPE covered surfaces the adherent HAC number was comparable to those on uncovered surfaces, and their proliferation after 3 days, as measured by metabolically active HAC, was improved. As an interesting side effect it was observed that HAC 
invaded more the voids and tunnels, if the porous Ti-6Al$4 \mathrm{~V}$ material was POPE-covered. This may open new possibilities to stimulate cell 'ingrowth' into porous metallic implant materials, though the question of nutrition transport remains unanswered. From this measurement it is evident that, to improve the stability and durability of the phospholipid layer, a covalent connection of the phospholipids with the metallic surface is a must for further studies. Still, even with loosely bound phospholipid layers, the following statements concerning the interaction between cells and the phospholipid coatings could be made:

1) As POPC elicited the expected repulsive effect on cell attachment, further on only POPE was considered as suitable coating for the metallic materials and the interaction with HAC or HMSC.

2) Beside the cell attachment, which is one parameter for the judgement of cell behaviour, as well as for the quality and suitability of a biomaterial, a variety of markers should be tested to gain better insight into the metabolism of cells on biomaterials. Here, one component of the cartilage matrix was chosen: chondroitin sulphate (CS) production. This molecule is part of the glycosaminoglycan (GAG) network surrounding chondrocytes in healthy cartilage. The quantitative determination of CS per cell (in units of DNA) showed that, independent of the glycosaminoglycan surface morphology, the formation of CS on POPE is increased by a factor of 1.3. Therefore, it can be deduced that the chondrogenic potential is significantly higher on either material with a POPEcoating, a promising aspect for tissue engineering. On the POPE-covered porous surfaces, the major part of HAC within the pores showed a more rounded shape (Figure $3 \mathrm{~b}$ ), which can either be a sign that the cells could not find adhesion points for attachment, or an indication for them remaining in the differentiated state of the chondrocytes (Glowacki et al., 1983; Schulze-Tanzil et al., 2002).

3) Similar positive effects were found for the interaction of HMSC on POPE-covered materials. Based on the encouraging results for $\mathrm{HAC}$, stem cells were grown on porous native and POPE-covered Ti-6Al-4V. The cells accepted the modified surfaces as well as the native surfaces, but without tendency to invade the POPE-covered pores, and they showed a much better performance in osteogenic differentiation on the phospholipids-covered surfaces. A detailed quantification is the subject of future studies. However, at this early stage, one can state that, with the phospholipid POPE-covering, an enhancement of biologically relevant HMSC functions can be stimulated in vitro.

The study of macrophage interaction with phospholipid covered surfaces showed that, in comparison to the primary positive control LPS, only minor reactions were found. Especially, that the phospholipid POPE did not induce any inflammatory reaction in terms of NO-production in vitro, which is a prerequisite for a successful application of this phospholipid coating in vivo. This experiment, however, considers only one aspect in the complex reaction of a body with respect to foreign materials. Future experiments, also in animal models, will elucidate if this camouflage by covalently-linked phospholipids is a promising approach for in vivo application.

\section{Conclusions}

It was shown that the coating of a metallic implant material by a biomembrane mimic, based on a single phospholipid, induces several effects depending on the cell types under observation. Here, the nature of the phospholipid is of special importance. As expected, the coating with POPC, which is an electrically neutral phospholipid, led to a strong decrease in cell adherence. In contrast, the influence of the slightly negatively charged POPE was very positive: POPE application together with a suitable surface morphology induces a synergistic effect on differentiation and matrix production for chondrocytes and stem cells. Despite the fact that chondrocytes are not the target cells for bone regeneration and implant attachment, the experiments - in combination with HMSC results - show the potential of a POPE-coating for tissue engineering or implant surface modifications which does also not activate macrophages. Whether this is due to charge effects or the biophysical properties of hexagonal phase formation by POPE will be a matter of future investigations.

In this study, which should be seen as a proof of principle, the interference of proteins from the growth medium with the phospholipids and/or the cells, was not taken into account. Still, our initial hypothesis is still valid that phospholipid surface layers - by interacting with proteins - are an important and so far not thoroughly considered aspect in cell-materials interactions.

\section{Acknowledgements}

The authors wish to thank Andreas Guse, Svenja Kuhnert, Peter Adamietz and Alexej Slobodiansky from the Institute for Medical Biochemistry and Molecular Biology, University Hospital Eppendorf, Hamburg for expert technical assistance and helpful discussions. Furthermore we appreciate the donation of cartilage by Klaus Püschel (University Hospital Eppendorf, Hamburg, Institute for Legal Medicine), RAW 264.7 cells by Andreas Gasser (University Hospital Eppendorf, Hamburg, Institute for Medical Biocmistry and Molecular Biology) and stem cells by Axel. R. Zander (University Hospital Eppendorf, Hamburg, Bone Marrow Transplantation Center). We are especially thankful to our colleagues Felix Beckmann and Tilman Donath (GKSS Research Center), who performed the $\mu \mathrm{CT}$ measurements, and DESY, Hamburg, for granting beamtime. Last, but not least, we wish to highly acknowledge the contribution of the scientific editor Hanns Plenk (Medical University of Vienna, Austria) who read the manuscript carefully and offered helpful comments and fruitful discussions.

\section{References}

Abbott J, Holtzer H (1966) The loss of phenotypic traits by differentiated cells. 3 . The reversible behavior of chondrocytes in primary cultures. J Cell Biol 28: 473-487.

Anishkin A, Kung C (2005) Microbial mechanosensation. Curr Opin Neurobiol 15: 397-405. 
Booth PJ (2005) Sane in the membrane: designing systems to modulate membrane proteins. Curr Opin Struct Biol 15: 435-440.

Boyan BD, Hummert TW, Dean DD, Schwartz Z (1996) Role of material surfaces in regulating bone and cartilage cell response. Biomaterials 17: 137-146.

Butler JH, Joy DC, Bradley GF, Krause SJ (1995) Lowvoltage scanning electron microscopy of polymers. Polymer 36: 1780-1790.

Chen JS, Juang HY, Hon MH (1998) Calcium phosphate coating on titanium substrate by a modified electrocrystallization process. J Mater Sci Mater Med 9: 297-300.

Cowan CM, Quarto N, Warren SM, Salim A, Longaker MT (2003) Age-related changes in the biomolecular mechanisms of calvarial osteoblast biology affect fibroblast growth factor-2 signaling and osteogenesis. J Biol Chem 278: 32005-32013.

Durrani AA, Hayward JA, Chapman D (1986) Biomembranes as models for polymer surfaces. II. The syntheses of reactive species for covalent coupling of phosphorylcholine to polymer surfaces. Biomaterials 7: 121-125.

Emoto K, Inadome H, Kanaho Y, Narumiya S, Umeda M (2005) Local change in phospholipid composition at the cleavage furrow is essential for completion of cytokinesis. J Biol Chem 280: 37901-37907.

Freed LE, Martin I, Vunjak-Novakovic G (1999) Frontiers in tissue engineering. In vitro modulation of chondrogenesis. Clin Orthop Relat Res 367 Suppl: S4658 .

Glowacki J, Trepman E, Folkman J (1983) Cell shape and phenotypic expression in chondrocytes. Proc Soc Exp Biol Med 172: 93-98.

Hayward JA, Chapman D (1984) Biomembrane surfaces as models for polymer design: the potential for haemocompatibility. Biomaterials 5: 135-142.

Holtzer H, Abbott J, Lash J, Holtzer S (1960) The loss of phenotypic traits by differentiated Cells in vitro, I. Dedifferentiation of cartilage cells. Proc Natl Acad Sci U S A 46: 1533-1542.

Ishihara K, Oshida H, Endo Y, Ueda T, Watanabe A, Nakabayashi N (1992) Hemocompatibility of human whole blood on polymers with a phospholipid polar group and its mechanism. J Biomed Mater Res 26: 1543-1552.

Iwasaki Y, Ijuin M, Mikami A, Nakabayashi N, Ishihara K (1999) Behavior of blood cells in contact with watersoluble phospholipid polymer. J Biomed Mater Res 46: 360-367.

Iwasaki Y, Nakabayashi N, Ishihara K (2001) Preservation of platelet function on 2methacryloyloxyethyl phosphorylcholine-graft polymer as compared to various water-soluble graft polymers. J Biomed Mater Res 57: 72-78.

Jennissen HP, Zumbrink T, Chatzinikolaidou M, Steppuhn J (1999) Biocoating of implants with mediator molecules: Surface enhancement of metals by treatment with chromosulfuric acid. Mat.-wiss. u. Werkstofftech 30: 838-845.

Kamata N, Fujimoto R, Tomonari M, Taki M, Nagayama M, Yasumoto S (2004) Immortalization of human dental papilla, dental pulp, periodontal ligament cells and gingival fibroblasts by telomerase reverse transcriptase. J Oral Pathol Med 33: 417-423.

Korematsu A, Takemoto Y, Nakaya T, Inoue H (2002) Synthesis, characterization and platelet adhesion of segmented polyurethanes grafted phospholipid analogous vinyl monomer on surface. Biomaterials 23: 263-271.

Kung C (2005) A possible unifying principle for mechanosensation. Nature 436: 647-654.

Labarca C, Paigen K (1980) A simple, rapid, and sensitive DNA assay procedure. Anal Biochem 102: 344352 .

Lewis AL, Cumming ZL, Goreish HH, Kirkwood LC, Tolhurst LA, Stratford PW (2001) Crosslinkable coatings from phosphorylcholine-based polymers. Biomaterials 22: 99-111.

Otto M, Franzen A, Hansen T, Kirkpatrick CJ (2004) Modification of human platelet adhesion on biomaterial surfaces by protein preadsorption under static and flow conditions. J Mater Sci Mater Med 15: 35-42.

Poltorak A, He X, Smirnova I, Liu MY, Van Huffel C, Du X, Birdwell D, Alejos E, Silva M, Galanos C, Freudenberg M, Ricciardi-Castagnoli P, Layton B, Beutler B (1998) Defective LPS signaling in C3H/HeJ and C57BL/ 10ScCr mice: mutations in Tlr4 gene. Science 282: 2085 2088.

Regunathan S, Piletz JE (2003) Regulation of inducible nitric oxide synthase and agmatine synthesis in macrophages and astrocytes. Ann N Y Acad Sci 1009: 2029.

Roessler S, Born R, Scharnweber D, Worch H, Sewing A, Dard M (2001) Biomimetic coatings functionalized with adhesion peptides for dental implants. J Mater Sci Mater Med 12: 871-877.

Schulze-Tanzil G, de Souza P, Villegas Castrejon H, John T, Merker HJ, Scheid A, Shakibaei M (2002) Redifferentiation of dedifferentiated human chondrocytes in high-density cultures. Cell Tissue Res 308: 371-379.

Schwartz DS, Shih DS, Lederich RJ, Martin RL, Denser DA (1998) Development and scale-up of the low density core process for Ti-64. Materials Research Society Symposium Proceedings 521: 225-230.

Simons K, Toomre D (2000) Lipid rafts and signal transduction. Nat Rev Mol Cell Biol 1: 31-39.

Smeets EF, Comfurius P, Bevers EM, Zwaal RF (1996) Contribution of different phospholipid classes to the prothrombin converting capacity of sonicated lipid vesicles. Thromb Res 81: 419-426.

Williamson P, Schlegel RA (2002) Transbilayer phospholipid movement and the clearance of apoptotic cells. Biochim Biophys Acta 1585: 53-63.

Willumeit R, Feyerabend F, Kamusewitz H, Schossig M, Clemens H (2003a) Biological Multi-layer Systems as Implant Surface Modification. Matwiss Werkst 34: 10841093.

Willumeit R, Kamusewitz H, Schossig M, Schröder J, Clemens H (2003b) Implant Surface Modification by Biological Multi-layer Systems. Materials Research Society Symposium Proceedings 734: B8.6.1-B8.6.6.

Willumeit R, Kumpugdee M, Funari SS, Lohner K, Navas BP, Brandenburg K, Linser S, Andra J (2005) 
Structural rearrangement of model membranes by the peptide antibiotic NK-2. Biochim Biophys Acta 1669: 125134.

Willumeit R, Schuster A, Iliev P, Linser S, Feyerabend F (2007) Phospholipids as implant coatings. J Mat Sci: Materials in Medicine 18: 367-380.

Wooley PH, Schwarz EM (2004) Aseptic loosening. Gene Ther 11: 402-407.

Zanchetta P, Guezennec J (2001) Surface thermodynamics of osteoblasts: relation between hydrophobicity and bone active biomaterials. Colloids Surf B Biointerfaces 22: 301-307.

Zreiqat H, Kumar RK, Markovic B, Zicat B, Howlett CR (2003) Macrophages at the skeletal tissue-device interface of loosened prosthetic devices express bonerelated genes and their products. J Biomed Mater Res 65A: 109-117.

Zwaal RF, Comfurius P, Bevers EM (1998) Lipidprotein interactions in blood coagulation. Biochim Biophys Acta 1376: 433-453.

\section{Discussion with Reviewers}

C Archer: The cartilage matrix production results can also be interpreted in the earlier scenario described for proliferation, since rounded chondrocytes synthesise more cartilage matrix than flattened ones.

Authors: We stated that the morphology of more rounded cells on the culture substrates can be interpreted as chondrocyte phenotype which was then proven by our matrix production data. Following this argumentation of reviewer 2, however, we should have found more chondroitin sulphate (CS) production on the native polished surfaces where a much higher number of rounded cells adhered and proliferated than on respective POPEcoated surfaces. In contrast, after we switched the cultures to chondrogenic differentiation and the cells began with matrix production, we found 1.3 more CS per cell on POPE-coated culture substrates. This increase was also independent of surface morphology, because on POPEcoated porous surfaces we even found slightly more cells than on respective native surfaces, and more cartilage matrix per cell was produced.

C Archer: There is no mention of culture medium analysis of CS which may harbour a high \% of the total CS produced, and there may not be any statistical differences in total synthesized CS between these groups.

Authors: The measurement of CS in the supernatant would be a possibility to determine the total amount of CS produced by the chondrocytes. In earlier studies on cartilage tissue engineering we have also performed this assay, but the CS yield in the medium was closely related to the amount of cartilage-like tissue formed. So, we think that the CS loss to the medium is of secondary interest.

C Archer: The criticisms of chondrocytes adherence, proliferation and differentiation also apply to these stem cell experiments.
Authors: Indeed, the initial adhesion of stem cells was not measured for our samples. As we compared stem cell adhesion only on the porous substrates, we relied on the data for chondrocyte adhesion, which were for these substrates comparable between native and POPE-coated surfaces. The measured DNA-amounts and thus stem cell numbers did not differ between POPE-coated and uncoated porous surfaces. For stem cells no such correlation between morphology and degree of differentiation is described in the literature, and was also not found in our study.

C Archer: How were the PCR samples normalized? The Figure 6 does not show their GAPDH reference bands. Again, 'significance' is stated but here no densitometric analysis has been carried out, and thus no firm (statistically proven) conclusion can be made in the absence of this analysis.

Authors: A new gel was made where both samples were running on the same gel for direct comparison, and this Figure 6 was replaced (now Figure 8), with all bands included and adjusted in size. Only visible differences were stated, but quantification has not been done yet because a densitometer was not available in our laboratory.

H Plenk: Was the $\mathrm{OsO}_{4}$ fixation/staining for LVSEM not interfering with cell recognition on the lipid layer?

Authors: Indeed $\mathrm{OsO}_{4}$ is interacting with lipids, which is visible in SEM and light microscopy. In the present study we therefore used secondary electrons at low accelerating voltage (to avoid using a metallic sputter coating), and then osmium is not detected. We prefer using osmium tetroxide as a postfixation method, because it improves the fixation of cellular structures and minimizes drying artefacts. Currently a comparison between the LVSEM (Low Voltage SEM) and backscattered electron imaging is in progress.

C Archer: This paper addresses an interesting concept of coating artificial implant materials with a lipid layer thus 'hiding' the implant material from recognition by adhering cells. It does not address what effect this has on the interactions with proteins which cells adhere to, such as fibronectin, vitronectin etc., although one suspects this is evident within the data.

Authors: Since this study was intended to be a first proof of principle we did not analyse all aspects of this complicated matter at once. Of course we are aware that the first interaction might take place between proteins from the growth medium and the lipid films (see, for example, Willumeit et al., 2003a). Currently we are investigating this issue in more detail. However, our initial hypothesis is still valid that the role of lipids in their interaction with proteins is an important and so far not thoroughly considered aspect in cell-materials interactions.

H Plenk: The concept of lipid covering, thereby "hiding" intact material surfaces from foreign body or immune responses seems erroneous, since aseptic loosening of the present metallic implants is rather due to corrosion products or particulate from the bulk metal or coatings, and from 
the gliding partners in artificial joints. Also, a porous titanium alloy (Ti6Al4V) has not yet been used for such an application because of mechanical strength and corrosion problems. Nothing is reported about possible influences of such a coating on the corrosion properties of the tested alloys.

Authors: The interesting result of these studies on phospholipid coatings seems the promotion of cell invasion and their differentiation on metallic substrates. The phosholipid coating is not thought to be improving corrosion resistance or reducing wear of implants.

H Plenk: While the metabolic effects of lipid covering were studied in macrophage cultures, nothing is reported on the stability of such coatings in the biological environment. The aggressive milieu of macrophages and foreign body giant cells has to be considered, if the lipid coating should withstand, until skeletal cells can colonize such a surface and start matrix production for the attachment of the implant.

Authors: As mentioned above, this study is a first proof of principles where many aspects are still to be considered. Together with partners in vivo studies are about to be performed. In addition, a covalent bonding of the lipids is our favoured way to improve the coating stability. We are still working on this topic. 